\title{
O DISCURSO DO/SOBRE ÓDIO NO CONTEXTO BRASILEIRO: NOSSO COMPROMISSO POLÍTICO COM O DIZER
}

\section{THE DISCOURSE OF/ABOUT HATE IN BRAZILIAN CONTEXT: OUR POLITICAL COMMITMENT WITH THE PHRASE}

\author{
Maria Cleci Venturini \\ Laboratório de Estudos Linguísticos e Literários-LABELL, UNICENTRO, Guarapuava, PR, \\ Brasil \\ Amanda Eloína Scherer \\ Laboratório Corpus-UFSM, Santa Maria, RS, Brasil
}

\begin{abstract}
Resumo: Propomos refletir sobre as razóes e as (des)razóes do discurso sobre/do ódio no contexto brasileiro na atualidade. Nosso ponto de destaque dar-se-á a partir da reflexão sobre o discurso - lugar material da ideologia - no qual ressoam memórias (discursos de) que sustentam e legitimam o discurso sobre o ódio que circula em uma dada formação social. Esse discurso sobre dá a ver um ponto de vista sobre a rejeiçáo em torno da cor vermelha, cor determinada como negação às realizaçôes de um governo com enfoque mais voltado ao social em políticas governamentais nos últimos tempos.
\end{abstract}

Palavras-chaves: Discurso; sujeito; memória; ódio; discurso de/sobre.

Abstract: We propose to reflect on the reasons and (dis)reasons of the discourse about/of hate in Brazilian context nowadays. Our point of prominence will be based on the reflection about the discourse - material place of ideology - where memories (discourses of) resonate, which sustain and legitimize the discourse about hate that circulate in a given social formation. This discourse about gives us a point of view upon the rejection of the color red, which is determined as a denial to the achievements of a government focused more in socially government policies in recent times.

Keywords: Discourse; subject; memory; hate; discourse of/about.

\section{Razóes e (des)razóes sobre um trabalho em parceria}

Temos como premissa acadêmica a produção do conhecimento dada e constituída pelo trabalho em parceria. Impossível projetar e prospectar um futuro científico sem que o institucional e o além-muros possam instar-se, construir-se e legitimar-se. Lutamos, desde sempre e muito mais na atualidade, por uma rede de relaçóes que acontecem em um vai e vem, 
primeiramente pela formação inicial de graduandos e depois, a partir desses mesmos graduandos, na formação da pesquisa e no trabalho em equipe. Nossa relaçáo constitutiva na escrita e na escritura do artigo que apresentamos aqui hoje traz um exemplo dessa nossa premissa, em uma parceria entre UFSM (Laboratório Corpus), Unicentro (LABELL) e Universidade de Cádiz, por meio da temática proposta pelos organizadores do referido número.

\section{Razóes e (des)razóes sobre um tema}

Vivemos tempos sombrios. Tempos de uma violência sem precedentes. Tempos de uma crise política, talvez, nunca vivida no país. Tempos de revolta e de revoltosos. Tempos presos a uma história política em um ideal que considerávamos ultrapassado. Tempos que ajudaram aflorar uma rejeição exacerbada pelo outro e do outro. Tempos de declaração pública de ódio. Tempos também desafiadores para todo cientista social, engajado em políticas públicas e preocupado com o futuro de nosso país.

Para nós, refletir sobre o discurso de/sobre ódio no contexto brasileiro da atualidade é trazer à baila um nó desafiador. Um nó enrolado nas condiçóes de produçáo atuais para podermos projetar açóes futuras. $\mathrm{Na}$ metáfora do nó, queremos dar a ver o quanto estamos todos enredados/ enrolados em uma crise política - náo só governamental - jamais vista na história de nosso país. Crise acelerada, sobretudo, por uma cultura de corrupção, cultura essa sem limites até os dias de hoje. Uma cultura sem limites na ética pública e por isso sem ética política. Uma cultura sem limites do que seria o bem público, agravada pelo sem limite entre o público e o privado. Uma crise sem limites do respeito ao outro, intensificada cada vez mais por um individualismo por demais marcado ideologicamente. Um sem limites institucional nas relaçóes público/privado, como já afirmamos, impedindo a construção e o desenvolvimento pleno de uma modernização mais voltada para o social brasileiro como um todo, impedindo, por sua vez, um possível furo no fosso histórico entre os que mais têm e os que nada têm.

Essa crise, sobretudo, levada a cabo pela grande mídia - privada, digase de passagem, dirigida por grandes corporaçóes de empresários sedentos em alimentar apenas o seu capital o -, através de meios de comunicação mais tecnológicos e contemporâneos, como é o caso das redes sociais, acabou trazendo à superfície também um ódio exacerbado. Ódio esse advindo de uma camada social que nunca esteve engajada pelos direitos sociais da sociedade como um todo. 
Como sabemos, nos últimos doze anos ${ }^{1}$, na história da governança brasileira, a política de estado foi mais voltada para uma parte específica da sociedade brasileira, àquela, quase sempre, ausente de políticas sociais historicamente constituídas. A referida governança conseguiu colocar em prática direitos que eram táo somente garantidos pela Constituiçáo e raramente colocados em jogo para o exercício efetivo da cidadania de grande parte da população. Ela acabou mostrando-nos, também, o quanto somos violentos em relação ao outro, não só na violência urbana causada por questôes econômicas e sociais, à deriva nos grandes centros extremamente cosmopolitas, mas sobretudo em relaçáo àqueles que tiveram apoio governamental, nos últimos tempos, para a concretude do seu bem estar enquanto sujeito cidadáo.

Estamos vendo, aos poucos, uma certa camada da população brasileira embrutecida e subjugada ao discurso da grande mídia, encontrando, na população em geral, sobretudo naquela da camada mais humilde, os seus inimigos e uma possível causa do nosso estado atual. À procura de culpados, diga-se de passagem, alimentada pela ideologia religiosa cristá, o ódio ajudou a justificar o golpe jurídico midiático que levou ao afastamento e ao impedimento de poder legal da presidente do Brasil, reeleita democraticamente nas últimas eleiçóes, realizadas em 2014. A partir daí, foi dada a largada (como em uma corrida em um hipódromo) para que, qualquer coisa que lembre ou que figure como sustentação ao governo que sofreu o golpe jurídico mediático, devesse ser colocada em questão, acentuando-se em um discurso violento, um discurso do ódio sobre o ódio a uma política de engajamento social.

Tudo que possa lembrar o governo afastado ou a ele referir-se ou, ainda, associar-se, ao principal partido anterior no poder, faz com que elementos mínimos da vida cotidiana sejam identificados como causadores e fazedores do mal, em um discurso quase sempre, repetimos, cunhado em uma formação discursiva religiosa. E, a partir dela, o bem contra o mal instala-se e vem servir ao discurso do e sobre o ódio. O bem contra o mal será a causa e a (des)razão da existência do discurso do e sobre o ódio. $\mathrm{O}$ bem contra o mal acaba configurando-se como aquele que virá salvar uma classe privilegiada daquela que nunca teve privilégios. O bem contra o mal vem sustentar um discurso que se diz o melhor e o mais justo. Mas de qual bem estamos tratando? Qual seria o mal que está em jogo discursivamente? Por que tanta dualidade? Por que acentuar cada vez mais fortemente tal dualidade?

\footnotetext{
${ }^{1}$ Fazem parte desses doze anos a eleição e posse de Luiz Inácio Lula da Silva (2003-2010) e o governo Dilma, também do PT (2011-2016). Dilma Rousseff foi afastada no dia 17 de abril, mas a votação do impeachment foi dia 31 de agosto de 2016.
} 
Não vamos responder, neste artigo, tais perguntas, o que vamos colocar, aqui, a partir de um exemplo, é o quanto uma camada social brasileira apoderou-se de um discurso de fundo religioso para justificar um mal social e um bem necessário, a ordem pré-estabelecida desde sempre. E, apoderando-se, embruteceu-se discursivamente, cegando-se para uma possibilidade de sociedade plural e heterogênea.

\section{Razóes e (des)razóes do discurso do ódio no contexto brasileiro}

As (des)razóes que elencamos anteriormente fazem-nos ver o quanto estamos vivendo o momento crucial de um liberalismo tardio - em que o discurso do ódio é praticado em relação às minorias, incluindo índios, negros, violência contra a mulher e questôes de gênero, alcançando as pesquisas e financiamentos, em que as ciências humanas assemelham-se ao "primo pobre" que ganha alguma coisa, mas sempre menos. O discurso do ódio, conforme Potiguar (2015), não é apenas uma manifestação locucionária, mas a ofensa em si mesma, que mais se aproxima da prática ilícita distanciada do Estado Democrático, que apaga as igualdades e se constitui como um desafio para a restauraçáo da democracia brasileira, a qual, segundo esse autor, tem praticado esse discurso no âmbito do direito, da política e até na Literatura, cerceando obras literárias, e nas Artes, cerceando exposiçóes artísticas em todas as suas manifestaçóes.

López-Muñoz $(2008$; 2015) tem desenvolvido pesquisas em torno discurso do ódio não só na Espanha, mas em outros países, dentre eles, o Brasil, a Tunísia e a Itália, dando a ver a intolerância e o ódio advindos dos homens, não só de naçôes. Para esse autor, o discurso fabrica a identidade e o real, não a partir de uma linha reta, mas por meio de uma zona difusa em que o trabalho da linguagem, na perspectiva enunciativa, pressupóe sujeitos, tempos, lugares e margens movediças. A fabricação de identidades e do real não acontece longe do funcionamento da ideologia, pela qual, por meio da língua, se constituem evidências que naturalizam os dizeres, tratados, por esse autor, por meio de enunciaçóes e atos de fala, os quais dáo visibilidade à irracionalidade do discurso do ódio dirigido então às minorias.

$\mathrm{Na}$ perspectiva discursiva em que nos inserimos, temos, como princípio teórico, o aparato proposto por Michel Pêcheux, que concebe o discurso como um lugar particular de articulação entre a linguagem e a ideologia. Para esse autor, o discurso define-se como efeito de sentido entre sujeitos, os quais, por sua vez, constituem-se na reversibilidade entre locutor e interlocutor, inscritos sempre em lugares sociais. Para tanto, não 
há possibilidade de sua realização na individualidade empírica, significando assim como um objeto social e histórico, no qual a língua é o lugar material da ideologia (PÊCHEUX, 1997). Dessa forma, é pela ideologia que se constituem as diferenças, as contradiçóes e os equívocos que estáo como se fossem apagados ou entáo visíveis pelo discurso no eixo da formulação, pela constituição de efeitos de homogeneidade e de saturação, como se o sentido estivesse dado, na linearidade do discurso. E no que concerne ao discurso do/sobre o ódio, destacamos Courtine (2014), por muitas razóes e (des) razóes, sendo a maior delas a relaçấo entre o linguístico e o ideológico.

$\mathrm{O}$ que queremos aqui não é só exemplificar o funcionamento desse discurso, mas também mostrar que a sua prática e recorrência fazem com que prolifere a irracionalidade e a cegueira, geradoras de constrangimentos, sustentadas, ao nosso ver, por uma memória religiosa que ressoa e divide a formação social entre o bem e o mal, o paraíso na terra e o paraíso no céu, tirando o foco da resistência e intensificando o discurso de aceitação e de rejeição a textualidades que tornam presente a luta de classes.

Conforme já sublinhamos, a divisão política do Brasil ocorre em espaços sociais, institucionais por meio de manifestaçóes discursivas que dâo visibilidade ao medo que as elites demonstram ter da esquerda e de um suposto "comunismo", representado pela cor vermelha. Esse medo que acaba se transformando em um discurso de ódio advém da memória, designada, por Courtine (2014), de memória discursiva. Essa é estruturada por repetiçóes, falhas, faltas, pelas quais ressoa um possível "comunismo" como representação de um mal ancorado pelo religioso e por nossa submissão econômica.

Alicerçados, do ponto de vista discursivo, e com vistas a dar a ver a repetibilidade, entendemos que os sujeitos-cidadãos - especialmente nas textualidades em análise - têm inscrito em dois espaços suas discursividades: a dos "vermelhos" e a dos "não-vermelhos", entendendo que esses últimos "jamais serão vermelhos". Essa divisão é histórica, mas se fortaleceu nos últimos doze anos de governança, principalmente através do Partido dos Trabalhadores (PT); primeiro, com Luiz Inácio Lula da Silva (2003-2010), e, depois, com Dilma Rousseff (2011-2016). Vale destacar o PT/Lula e a individualização do Partido, pela relação metafórica que fazia, do UM, o OUTRO, sendo Lula e PT uma significaçáo como pertencentes a um mesmo domínio.

Essa rede metafórica não se constitui por acaso, nem somente porque Luiz Inácio Lula da Silva foi presidente do Brasil em dois mandatos e elegeu a sua sucessora, Dilma Rousseff. Também se constitui porque Lula foi um 
dos fundadores do PT, cujo manifesto foi publicado em 10 de fevereiro de 1980, há trinta e oito anos, em um período de forte resistência ao regime ditatorial, iniciado em 1964, quando a democracia e o Estado de Direito foram extintos. Durante quase vinte anos, os militares governaram o Brasil com uma mão de ferro, valendo-se de Atos Institucionais e da restrição e extinção das liberdades.

Naquele período, Lula, sindicalista e militante de esquerda, foi reconhecido como liderança política forte e atuante. Participou das "Diretas Já" - como ficou conhecido o movimento que pedia a retomada da democracia - e, desde 1989, ano da primeira eleição direta, candidatou-se à presidente do Brasil, configurando-se, desde então, como um dos principais alvos do discurso do ódio, manifesto pela discriminação social, racial e cultural que gerou a rejeição de um candidato nordestino e sem curso superior, repetindo a prática recorrente em relação às minorias nominadas anteriormente.

No que tange ao "vermelho", recorremos a Indursky (2003) para dizer que a motivação do ódio, bem como a divisão dos sujeitos cidadáos, vêm de textualidades que já circularam antes, em outros lugares, tendo em vista que qualquer discurso constitui-se por muitas textualidades que ressoam nele e pela memória (discurso de) que sustenta a atualidade - o discurso sobre (VENTURINI, 2009). Nesse sentido, indiciamos que a representação do mal ressoada pelo vermelho remete a um certo estereótipo do que poderia ou deveria ser comunismo e às textualidades que "habitam" a palavra em si, não como palavra, mas como textualidade que instaura e, ao mesmo tempo, traz à tona redes metafóricas através de um discurso transverso decorrentes de atravessamentos não linearizados no fio do discurso, os quais "fazem" e "preenchem" possíveis "furos" no dizer.

$\mathrm{O}$ que teremos é a possibilidade de o grupo nominado como "não vermelhos", que desliza para "jamais seremos vermelhos" ser protagonista das manifestaçóes de ódio, referendando o que destaca Pêcheux (1997) em relaçáo ao discurso dependente do sujeito e deste sempre afetado/ interpelado pela ideologia. Desse modo, seguimos López-Muñoz (2015, p. 10), para quem o discurso é "como um traço da história", e a perspectiva discursiva em que o discurso existe estabelece-se pela relação do linguístico com o ideológico, portanto de sujeitos interpelados pela ideologia, como o lugar material da língua na história, construindo efeitos de saturação e de homogeneidade. Não podemos afirmar que o discurso do ódio, no Brasil, é recente, tampouco que teve início nos últimos doze anos, mas sublinhamos que ele se acentuou muito e centralizou-se no "vermelho" como a cor da 
resistência, de uma possível bandeira comunista e, associado ao vermelho, a cor representante também do PT.

Como sabemos, Luiz Inácio Lula da Silva, ex-metalúrgico e dirigente sindical, foi um dos fundadores do PT, tendo sido o seu presidente de honra. Atuou nos movimentos políticos brasileiros, dentre eles, na campanha "Diretas Já", em 1984, em que um grupo de brasileiros mobilizouse, buscando a eleição para a presidência do Brasil. Além disso, ele foi candidato à presidente do Brasil desde a primeira eleição direta, em 1989, sendo derrotado em três pleitos; muito possivelmente, como consequência, está o discurso de rejeição e de aversão ao "vermelho", que representa o seu partido e, dentro dele, as políticas que vislumbram uma sociedade mais inclusiva. Somente na eleição de 2002 é que o PT venceu as eleiçôes e seu candidato assumiu a presidência da república. Com Lula na presidência, o discurso do ódio teve um aumento considerável, seja porque o "vermelho" que representa o partido teve maior visibilidade, seja porque, de tanto se dar à repetição, acaba instaurando uma nova série de repetiçóes e, com isso, constituindo o que estamos definindo como discurso do ódio.

O discurso do ódio é mais do que um discurso de oposição, pois a sua repetição e a sua expansão têm colocado em risco a liberdade de expressão, promovendo uma divisão entre dois domínios antagônicos, aqueles constituídos pelos "vermelhos" (PT e petistas) e os "não-vermelhos" (todos os que rejeitam o PT). Essa divisão fez tanto sentido no contexto político brasileiro que os cidadãos não olhavam mais para as plataformas dos candidatos à presidente do Brasil, o foco concentrou-se no desejo de tirar os "vermelhos" da presidência. Nesse funcionamento, o vermelho instaura uma rede metafórica sustentada em instâncias imaginárias e discursivas, divididas entre o bem e o "mal", que "os vermelhos" representam o mal e os "não-vermelhos" o bem, englobando múltiplos sentidos. Assim, tal formação imaginária e discursiva tenta apagar os avanços sociais dos últimos doze anos, buscando desconstruir o período em que estiveram na presidência da república brasileira representantes do PT, representados pelos governantes Luís Inácio Lula da Silva (2002-2010) e Dilma Rousseff (2011-2016).

\section{Razóes e (des)razóes de uma relação teórica e analítica}

Estamos desde sempre projetando nossas questôes analíticas na sustentaçáo de certas textualidades e na memória que retorna ou não. Dessa forma, tomamos redes de memória centradas no desejo de "fazer memória”, tal como propóe Certeau (1994), e, também, na celebração, pela 
qual certas memórias "deveriam" permanecer e outras "deveriam" continuar subterrâneas, adormecidas nos poróes da História. Entretanto, como assinalou Nora (1994), em relação aos "lugares de memória", nem sempre o "planejado" e o "desejado" seguem a regularidade prevista, dando início a uma nova série, que poderia constituir-se em um acontecimento discursivo, de acordo com Pêcheux (1999), ou "como o ponto em que o impossível (o linguístico) vem aliar-se à contradição (histórica); o ponto em que a língua atinge a História" (GADET; PÊCHEUX, 2004, p. 64).

Diante desses impulsos e questôes, distinguimos o discurso do (como origem) e o discurso de (como memória) e, diferenciamos, também, o discurso sobre (como assunto) do discurso sobre (como atualidade) ${ }^{2}$. Nesse sentido, vemos o funcionamento de um discurso do ódio, que fundamenta o ódio; mas esse discurso, sendo do, liga-se a sujeitos ou a posiçóes-sujeito, sendo distinto do discurso de, entendido como memória que preenche os furos no discurso sobre. O discurso de funciona como um discurso que sustenta e ancora o discurso sobre, a partir do eixo da constituição, memória ou interdiscurso, de acordo com Pêcheux (1997), e se inscreve no eixo vertical, o eixo paradigmático, em que duas memórias não se sobrepóem, assim como dois objetos não ocupam o mesmo lugar. $\mathrm{O}$ discurso de funciona como o que está já-lá, repetindo-se parafrasticamente, entendendo-se, aqui, a paráfrase, a partir de Orlandi (1999, p. 36), como processos "pelos quais em todo o dizer há algo que se mantém, isto é, o dizível, a memória”.

Já o discurso sobre possui dois funcionamentos: um em que ele instaura um discurso pedagógico e assemelhar-se-ia ao falar $d e$, e o outro funcionamento, que é o discurso sobre como atualidade, o reverso do discurso de, constituindo-se por meio de metonímias, como o que instaura e constitui a discursividade, no eixo da formulação - o sintagmático -, em que ocorrem as associaçóes na sua formulação e que se inscreve em (dis)curso sufocados pela memória. Nesse funcionamento, o discurso de e o discurso sobre caminham juntos na materialidade discursiva, devido à impossibilidade de se separar o que é da memória e o que é da atualidade (VENTURINI, 2009). É o que entendemos ser a memória discursiva: memória e atualidade, em (dis)curso, como processo, sempre "se instando" e instaurando efeitos de sentidos. Vamos aqui trazer um pequeno exemplo, a partir de uma questáo analítica, para tentar entender o funcionamento desse discurso a partir de acontecimentos em torno do "vermelho", que retoma uma cor como aquela que instauraria uma possível constituição do discurso do/sobre o ódio em um país dividido não somente em classes, mas por textualidades, muitas

${ }^{2}$ Venturini (2014). 
vezes, pautadas no senso comum, sem sustentação, mas com manifestaçôes em favor "do vermelho" e "contra o vermelho".

Conforme sinalizado anteriormente, nesse período, funcionavam duas posições "vermelhas" - a favor do PT e dos que representam o partido e "a náo-vermelha", contra o PT e a favor de qualquer outro partido, incluindo a aceitação de uma nova intervenção militar, se necessário. Essa dualidade que dividiu o país e os cidadáos fez instar outras designaçôes das quais não vamos tratar aqui por demandar um espaço ainda maior linguística e discursivamente.

Passamos ao que estamos propondo como objeto de análise. No dia 16 de novembro de 2016, uma das vozes que defendia a intervençáo militar invadiu/ocupou o plenário da Câmara. $\mathrm{Na}$ entrada do referido espaço, havia, no seu mural principal, a bandeira japonesa, sobreposta à brasileira, como representação à comemoraçáo ao centenário da imigraçáo japonesa no Brasil. A manifestante, obcecada pela cor vermelha, acaba construindo um fato demasiadamente grotesco, indiciando o vermelho de tal bandeira como aquele que estaria representando o comunismo (texto-imagem 1).

Para demonstrar uma das manifestaçóes de ódio, recortamos do vídeo postado por Fernanda de Morais ${ }^{3}$, em 16 de novembro de 2016, uma mulher que "confunde" a bandeira do Japão com a bandeira do Brasil. Nessa tomada, esse sujeito mostra-se indignado com o que "pensa" ser uma alteração na bandeira do Brasil. Conforme a SD 01, no vídeo, a mulher descreve a cena. O que nos interessa destacar aqui, em termos de textoimagem, é o modo como esse sujeito "fala", especialmente, o tom de voz e a postura "professoral" com que alerta os brasileiros sobre o que considera "mudança" na bandeira. Nesse texto-imagem, atrás da mulher está a bandeira do Japão e ela usa a bandeira para ilustrar "a cena".

A manifestante - integrante do grupo dos "não vermelhos" -, de forma "teatral", faz um apelo à populaçáo em geral, servindo-se de imperativos para que eles próprios pudessem/devessem se dar conta do apagamento das cores verde e amarelo que representariam a nação brasileira, trazendo a cor vermelha em uma ilha de incompreensão e embrutecimento, conforme destacamos, a seguir, a partir de sua narrativa e do qual recortamos as sequências discursivas que dão visibilidade ao funcionamento do discurso que queremos apresentar. Vejamos:

\footnotetext{
${ }^{3}$ Disponível em: <https://www.youtube.com/watch?v=PnCCZ0buRQc>. Acesso em: 10 jan. 2018.
} 
No congresso Nacional, nós nos deparamos com uma cena nojenta, nojenta. Reparem aqui, a nossa bandeira com o símbolo vermelho comunista. Veja o que está acontecendo. Essa será a nova bandeira do Brasil. Preparem-se brasileiros, você incauto, que ainda não se deu conta do que está acontecendo no Brasil, fique esperto. Olha isso, a nossa bandeira não será mais como nós conhecemos. Veja ...

É importante destacar o tom de voz, aliado à postura professoral da manifestante, constituindo efeitos de ela saber o que diz e de que, da posição-sujeito que ocupa, pode/deve dizer o que diz, podendo entrar na "ordem do discurso", podendo legitimamente asseverar que a bandeira brasileira mudou, que não "será mais como a conhecemos", instaurando um discurso autorizado, pautado no senso comum, mas recheado de juízos de valores, constituídos e, acima de tudo, pelo funcionamento da subjetividade, encarcerada no seu ódio à cor vermelha.

Entendemos que ao designar o outro de INCAUTO, pedindo para que fique ESPERTO, a manifestante se significa porque ela "sabe/conhece" os riscos que o símbolo nacional - bandeira - corre porque recebeu o SíMBOLO DO COMUNISMO. Quando se "significa" como sujeito autorizado a dizer o que diz, a manifestante dá visibilidade ao funcionamento do discurso político e à luta de classes, mostrando a divisão entre, de um lado, o sujeito destituído do senso crítico e, de outro, o sujeito que se "vê" como aquele que sabe que pode/deve dizer ao "outro", o que ELE deve/pode fazer, isto é, precisa/deve deixar de ser incauto, precisa/deve ser esperto.

Nesse discurso, ressoa a projeçáo imaginária do sujeito que fala sobre ele mesmo, autorizando-a a dizer o que diz e do interlocutor, como o inocente. No entanto, o sentimento de nacionalidade e, talvez, o desejo de convencer o "outro" a abandonar o lado dos "vermelhos" em que se inscreve, ressoa pelo A NOSSA BANDEIRA, O SIMBOLO MÁXIMO DO NOSSO PAÍS, incluindo o "outro" para juntos serem contra a onda de vermelho que assola o país. Ressoa forte, também, o discurso do/sobre o ódio ao "vermelho" e, por consequência, ao comunismo. Encerra uma totalidade do tipo: eles são VERMELHOS, portanto comunistas e ela, a manifestante, está do outro lado do "não vermelho", portanto ela faz parte daqueles que SÃO contra os "vermelhos", que jamais "serão vermelhos".

Sendo assim, os efeitos de sentidos se constituem pela língua na história, a partir de uma base linguística sim, mas em processos discursivos dados 
pela formação de redes metafóricas pelas quais "vermelho", de um lado, ligase à resistência e à luta, o que se conhece como "esquerda revolucionária", que busca a transformação no contexto brasileiro, a manutenção do PT no poder ou, pelo menos, de rejeição à volta do militares. De outro lado, "o não-vermelho" constitui redes com tudo que não for vermelho, ressoando em outro lugar, o lugar privilegiado de uma certa classe social.

Como sabemos, a partir de Pêcheux (1997), o sujeito inscreve seu dizer em uma formação discursiva por identificaçóes e filiaçóes que autorizam certos dizeres e interditam outros na produção do seu discurso. No entanto, devido à interpelação ideológica e ao atravessamento do inconsciente, o sujeito náo tem consciência de que o seu dizer emana do interdiscurso - lugar em que ele, de acordo com Pêcheux (1997) busca saberes que o autorizem. O que sustenta esse discurso sobre (atualidade) é o discurso de, como memória, pela qual o vermelho é a cor da resistência ao poder constituído, predominantemente filiado a uma certa representação de comunismo, negado por formulaçóes que, segundo Indursky (2003) antecedem o discurso comunista no Brasil. Essa memória e o discurso que se sustenta nela, ressoa desde a Encíclica de Pio XI, publicada em Roma, em 19 de março de 1937, destacando o "Comunismo ateu", filiando o comunismo ao mal, à falsidade, à destruição da família e à falsa ajuda aos pobres .

O discurso do ódio "faz ver" o vermelho em todos os lugares e instaura náo somente o medo, mas também o pavor, que resulta em discurso do ódio que embrutece/emburrece/estarrece na tensão entre o mesmo e o diferente. Nessa sequência, a rede parafrástica instauradora da repetição, dá visibilidade à divisão entre vermelhos e não-vermelhos, em que os primeiros são comunistas e culpados por todos os males que assolam o Brasil e, os segundos são os defensores da Pátria. Poderíamos resumi-la da seguinte forma:

\footnotetext{
${ }^{4}$ Para aprofundamento sobre o ideário comunista no Brasil, sugerimos o texto Mariani (1997).
} 
Vermelho é comunista

O comunismo é do mal e é vermelho

O PT é vermelho, por isso É DO MAL

A mídia engloba TODOS os vermelhos, destacando que TODOS são corruptos e são PT.

Os vermelhos (PT) estão no poder e vão mudar tudo, inclusive a bandeira do Brasil.

Os vermelhos (PT) são todos corruptos, perigosos e mentirosos.

Revisitamos o segundo vídeo 5 , no qual a manifestante volta para esclarecer o "equívoco". Interessa-nos sinalizar a expressão de "vítima" no seu rosto, ressoando um engano provocado pelo momento político no qual o Brasil se encontra: tal situação é que fez com que ela confundisse as duas bandeiras. Fizemos esse recorte porque ele é significativo e dá visibilidade ao "medo" e ao "ódio" a tudo que pudesse encaminhar para "o vermelho", pelo qual ressoam memórias do comunismo.

O discurso sobre e o discurso do ódio - que vem de um sujeito, não vermelho, viralizou nas redes sociais, mostrando como uma presença na ausência "pode" instaurar o logro, o equívoco. É o que sinaliza o recorte 02, quando o mesmo sujeito volta a gravar um vídeo para "explicar" o equívoco, mostrando, inclusive, que os manifestantes não "eram" uma parcela significativa de brasileiros, mas apenas nove pessoas.

O texto-imagem 02 diz muito mais do que o próprio dizer e isso ocorre por meio do que se vê, funcionando como discurso que inscreve o dizer em redes de memória, instaurando efeitos de sentidos. Nele ressoa como memória, um sujeito rouco, abatido e, por meio dessa "aparência" física, o funcionamento do imaginário de brasileiro que perdoa e se comove diante de uma cena mais triste, segundo o que diz Orlandi (1999) sobre a antecipação imaginária. Em resumo, uma voz rouca e um rosto triste pode fazer "esquecer" o sujeito arrogante que minimiza os demais sujeitos e "confunde" uma bandeira com outra, convocando os brasileiros a "ver" o que não existe.

$\mathrm{O}$ vídeo inicia com a manifestante narrando o acontecido, informando que ela e mais nove pessoas foram ao congresso para pedir o fim da corrupção e a volta dos militares. Ela se mostra bastante incomodada, como se pode ver na sequência a seguir:

${ }_{5}^{5}$ Disponível em: <https://www.youtube.com/watch?v=k6yCgewZ93I>. Acesso em: 10 jan. 2018. 
O motivo de fazer esse vídeo é porque dias atrás, eu e mais nove patriotas nos deparamos com uma parede com a bandeira do Brasil e tinha ali a bandeira do Japáo. Fomos todos tomados por a sensaçáo de um sentimento de que ali poderia estar havendo uma desconstruçáo da bandeira do Brasil porque de fato isso já isso já houve. Todos sabem em Copacabana o que aconteceu, e de fato eles têm projetos já, praticamente decisivos né, logo mais em mudar a nossa bandeira [...]. Acho que foi isso se não me engano [...]. Mas enfim tomados todos nós por esse sentimento de que poderia estar havendo ali uma desconstruçáo do símbolo máximo do nosso país, teve esse equívoco com a bandeira do Japão que náo é comunista.

Nessa sequência, a manifestante grava um vídeo com o objetivo de explicar o que chama de "equívoco". Assume a posição-sujeito, vítima de um equívoco, causado por "outros" fatos acontecidos anteriormente. Explica que ela e mais NOVE PATRIOTAS foram tomados por um SENTIMENTO DA SENSAÇÃO de que PODERIA estar havendo UMA DESCONSTRUÇÃO DA BANDEIRA DO BRASIL.

Mesmo travestindo-se de "vítima de um equívoco", mais pelo que o texto-imagem permite dar a ver, o sujeito continua colocando-se como legitimado para dizer o que diz. Há um efeito importante de que toda a "emoçáo" se deve ao fato dela ter passado por "ignorante", "apressada", "ansiosa", "tomada pelo pânico" do que um pedido de desculpas, que poderia ter sido feito por alguém que confunde uma coisa com outra e se coloca como detentora de um saber que mostra, de fato, não possuir. Poderíamos ainda, levar em conta, o tipo de verbalizaçáo e o tempo verbal em si, pois todos estáo no futuro do pretérito e que constituem, ao nosso ver, efeitos de sentido de uma totalidade absurdamente possível. Além disso, TODOS, são apenas dez pessoas. Mas TODOS são PATRIOTAS. A rejeiçáo ao VERMELHO acaba ressoando pelas redes de memória, fazendo vir à superfície, o discurso do ódio, pelo qual se "ouve", no que não está dito, mas latente através da intimidação. De fato, a bandeira "deles" do TODOS - estaria sendo mudada do verde amarelo para vermelha em uma "presença-ausente", em consonância com Courtine (1999) em "Chapéu de Clementis", que continua ressoando e constituindo efeitos, mesmo não estando fisicamente presente, ou como diz Orlandi (2002, p. 13) em relação ao silêncio "como iminência do sentido". 
A rede parafrástica que se constitui a partir da sequência 02 pode ser resumida da seguinte forma:

Nós - patriotas somos aqueles que rejeitam o vermelho e o comunismo.

O vermelho representa a desconstrução do símbolo máximo do Brasil.

"Eles" é a nomeação para os vermelhos.

Nós não "erramos", na verdade "acertamos" ou no máximo houve um equívoco.

Palavras como: "poderia" e "praticamente decisivos" passam a significar CERTEZA e mais CONDICIONALIDADE.

Todos nós são dez pessoas.

\section{Razóes e (des)razóes: efeito de conclusão}

A proposta deste texto foi refletir sobre as razōes e (des)razóes do/ sobre o discurso do ódio no contexto brasileiro na atualidade, significando-o como compromisso político, ilustrado por uma relação com o "vivido". Inscritos nessa ordem do vivido, recortamos, não "segmentamos" um fato que dá visibilidade ao discurso do ódio, ressoando a intimidação, quando uma minoria se projeta e se significa como um "TODO", autorizando-se a falar em nome de muitos, de uma totalidade de 10 sujeitos. $\mathrm{Na}$ ordem do vivido, o TODO aqui colocado, mostra-se, mas na ilusão do sujeito de poder dizer o que diz e de ser a origem do dizer. Para nós, seria uma textualidade ilustrativa dos modos de funcionamento do discurso do ódio no contexto brasileiro da atualidade. Do nosso ponto de vista, o discurso do ódio projeta-se em um devir incondicional e o discurso sobre o ódio se faz ver pela cegueira que emburrece e instauram a saturação. Os argumentos fortalecem-se no discurso do ódio dando sustentaçáo para que o discurso sobre o ódio possa ressoar, como memória e ancorar/sustentar posiçóes políticas e ideológicas historicamente constituídas. E, para construir um efeito de fechamento para algo que náo se fecha, as textualidades constroemse a partir de algo que já circulava antes e, muitas vezes, de discurso que constitui, conforme Courtine (2014) em um efeito-origem, funcionando como um discurso de, que atualiza os sentidos, significando a língua em relação à história, que apesar de não ser cronológica, constitui sentidos. 
Entre a cor que poderia vir a ser e a cor que seria ela a representaçáo de ideias, o ódio faz nascer uma contradição entre o vermelho do mal e o vermelho do bem, o vermelho do sangue que corre nas veias de todos os brasileiros, sejam eles vermelhos e ou todos coloridos e matizados pelo que somos na atualidade. Entre o vermelho e o não vermelho, a vida política, social, econômica, histórica segue seu rumo.

\section{Referências}

COURTINE, Jean-Jacques. O Chapéu de Clémentis. Tradução de Brás de Rodrigues, M.R. In: Indursky, F.; Leandro Ferreira, M. C. (Org.). Os múltiplos territórios da Análise de Discurso. Porto Alegre: Sagra Luzzatto, 1999.

Análise do discurso político: o discurso comunista endereçado aos cristáos. São Carlos, SP: EDUFSCar, 2014.

CERTEAU, Michel de. A invenção do cotidiano. Artes de fazer. Tradução de Ephraim Ferreira Alves. Petrópolis, RJ: Vozes, 1994.

GADET, Françoise; PÊCHEUX, Michel. A língua inatingível: o discurso na história da linguística. Campinas: Pontes, 2004.

INDURSKY, Freda. Lula lá: estrutura e acontecimento. Revista Organon, Porto Alegre: UFRGS, v. 17, n. 35, p. 01-21, 2003.

LÓPEZ-MUÑOZ, Juan Manuel. Aproximación a la circulación de discursos: la repetición em los foros de prensa digital. In: Hispanismo, 2006, Estudos da Linguagem, Rio de Janeiro, p. 49-65, 2008.

Aux marges du discours: personnes, temps, lieux, objets. Actes du $X^{\circ}$ Congrès International de Linquistique Française, Cadiz, reunis et présentés 227-29, novembre, 2013.

MARIANI, Bethânia. O comunismo imaginário: práticas discursivas da imprensa sobre o comunismo. In: POSSENTI, S. (Org.). Sínteses - Teses. 01 ed. Campinas: IEL - Unicamp, 1997.

NORA, Pierre. Entre mémoire et histoire. La problématique des lieux. In:__Les lieux de mémoire, Paris: Gallimard, 1994, v. I.

ORLANDI, Eni Puccinelli. Análise de Discurso: princípios e procedimentos. Campinas/SP: Pontes Editores, 1999. 
. Formas do silêncio no movimento dos sentidos. Campinas: Unicamp, 2002.

PÊCHEUX, Michel. Semântica e discurso: uma crítica à afirmação do óbvio. Campinas: UNICAMP, 1997.

. Papel da memória. In: ACHARD, Pierre et al. Papel da memória. Tradução e introdução de José Horta Nunes. Campinas, SP: Pontes, 1999.

POTIGUAR, Alex Lobato. Discurso do ódio no Estado Democrático de Direito: o uso da liberdade de expressão como forma de violência. 2015. Tese (Doutorado em Direito). Universidade de Brasília, Distrito Federal, 2015. Disponível em: <http://repositorio.unb.br/ bitstream/10482/20702/1/2015_AlexLobatoPotiguar.pdf>. Acesso em: 10 dez. 2017.

VENTURINI, Maria Cleci. Imaginário urbano: espaço de rememoração/ comemoração. Passo Fundo/RS, Editora da UPF, 2009.

Mídia, ruído e silêncio tumular na constituição contraditória da memória em curso/discurso. In: TASSO, Ismara; SILVA, Érica (Org.). Lingua(gens) em discurso: a formação de objetos. 1. ed., Campinas: Pontes, v. 08, 2014, p. 119-136. 